Article

\title{
Accelerating the Mdx Heart Histo-Pathology through Physical Exercise
}

\author{
Jacopo Morroni ${ }^{1}$, Leonardo Schirone ${ }^{2}$, Daniele Vecchio ${ }^{2}{ }^{-}$, Carmine Nicoletti ${ }^{1}$, Luca D'Ambrosio ${ }^{2}$, \\ Valentina Valenti ${ }^{3}$, Sebastiano Sciarretta ${ }^{2,4}$, Biliana Lozanoska-Ochser ${ }^{1,+}$ and Marina Bouchè ${ }^{1, *,+}+\mathbb{C}$
}

1 Department of Anatomical, Histological, Forensic Medicine and Orthopedic Sciences, Section of Histology and Embryology, Sapienza University of Rome, 00161 Rome, Italy; jacopo.morroni@uniroma1.it (J.M.); carmine.nicoletti@uniroma1.it (C.N.); biliana.lozanoska-ochser@uniroma1.it (B.L.-O.)

2 Department of Medical and Surgical Sciences and Biotechnologies, Sapienza University of Rome, 00161 Rome, Italy; leonardo.schirone@uniroma1.it (L.S.); daniele.vecchio@uniroma1.it (D.V.); L.dambrosio@uniroma1.it (L.D.); sebastiano.sciarretta@uniroma1.it (S.S.)

3 Department of Cardiology, Ospedale Santa Maria Goretti, 04100 Latina, Italy; valevale2012@hotmail.com

4 IRCCS Neuromed, Via Atinense 18, 86077 Pozzilli, Italy

* Correspondence: marina.bouche@uniroma1.it

+ Co-senior authors.

Citation: Morroni, J.; Schirone, L.; Vecchio, D.; Nicoletti, C.; D’Ambrosio, L.; Valenti, V.; Sciarretta, S.;

Lozanoska-Ochser, B.; Bouchè, M Accelerating the $M d x$ Heart HistoPathology through Physical Exercise. Life 2021, 11, 706. https:/ / doi.org/ $10.3390 /$ life11070706

Academic Editor: Gopal J. Babu

Received: 9 June 2021

Accepted: 14 July 2021

Published: 17 July 2021

Publisher's Note: MDPI stays neutral with regard to jurisdictional claims in published maps and institutional affiliations.

Copyright: (C) 2021 by the authors Licensee MDPI, Basel, Switzerland. This article is an open access article distributed under the terms and conditions of the Creative Commons Attribution (CC BY) license (https:// creativecommons.org/licenses/by/ $4.0 /)$.

\begin{abstract}
Chronic cardiac muscle inflammation and fibrosis are key features of Duchenne Muscular Dystrophy (DMD). Around 90\% of 18-year-old patients already show signs of DMD-related cardiomyopathy, and cardiac failure is rising as the main cause of death among DMD patients. The evaluation of novel therapies for the treatment of dystrophic heart problems depends on the availability of animal models that closely mirror the human pathology. The widely used DMD animal model, the $m d x$ mouse, presents a milder cardiac pathology compared to humans, with a late onset, which precludes large-scale and reliable studies. In this study, we used an exercise protocol to accelerate and worsen the cardiac pathology in $m d x$ mice. The mice were subjected to a $1 \mathrm{~h}$-long running session on a treadmill, at moderate speed, twice a week for 8 weeks. We demonstrate that subjecting young $m d x$ mice (4-week-old) to "endurance" exercise accelerates heart pathology progression, as shown by early fibrosis deposition, increases necrosis and inflammation, and reduces heart function compared to controls. We believe that our exercised $m d x$ model represents an easily reproducible and useful tool to study the molecular and cellular networks involved in dystrophic heart alterations, as well as to evaluate novel therapeutic strategies aimed at ameliorating dystrophic heart pathology.
\end{abstract}

Keywords: DMD; $m d x$; exercise; fibrosis; heart; animal model

\section{Introduction}

DMD is an X-linked genetic disease caused by mutations in the dystrophin gene. The lack of functional dystrophin destabilizes the muscle sarcolemma, causing progressive muscle damage [1-3]. Chronic inflammation in both skeletal and cardiac muscle leads to fibrotic tissue deposition that impairs muscle function [1-4]. It is estimated that almost $60 \%$ of 10-year-old boys present clear signs of cardiomyopathy, and this percentage increases up to $90 \%$ among 18-year-old patients [4-6]. Along with respiratory failure, cardiac failure represents the main cause of death in DMD patients $[1,3,4]$.

At present, there is no cure for DMD, and the only recommended treatment is the use of corticosteroids $[1,3,4]$, supporting the notion that the inflammatory compartment plays an important role in disease progression. Corticosteroid treatment slows down DMD progression in skeletal muscle, delaying the loss of ambulation and the need for assisted ventilation by improving muscle strength and dampening inflammation [1,3]. However, long-term use of corticosteroids is associated with severe adverse effects, including bacterial and viral infections, as well as metabolic disorders. Although corticosteroids are believed to 
be effective in delaying cardiomyopathy onset in DMD patients, there is some controversy regarding the reliability of several large-scale studies [4,5]. There is therefore an urgent need for novel therapeutic approaches for the treatment of cardiomyopathy in DMD. In order to evaluate the effectiveness of novel therapeutic approaches, it is essential to have at our disposal appropriate animal models that genetically and phenotypically mirror the human pathology. The widely used DMD animal model, the $m d x$ mouse, resembles the human pathology in terms of the genetic mutation and early skeletal muscle phenotype [7-9]. However, the disease progression is quite different in comparison to human patients [9]. For example, the lifespan of $m d x$ mice is only $20 \%$ lower than that of wild-type mice [10], while human patients, without assisted ventilation, die before they reach 25 years of age [11,12]. Moreover, $m d x$ mice present a milder cardiac pathology compared to human patients, with a slower onset and strong individual variation [7-10]. The absence of an animal model that closely resembles the severity of DMD cardiomyopathy has hindered large-scale and reliable studies of potential therapeutic strategies aimed at ameliorating the dystrophic heart phenotype. Previous studies have described different mouse models displaying worsened heart pathology that were generated by additional genetic manipulations [8], such as deletion of utrophin in the double mutant $m d x /$ utrn- $-[13,14]$, which was recently further manipulated to resemble human heart pathology in the Fiona/dko mouse model [15]. Another strategy was to eliminate or humanize the telomerase gene in $m d x$ mice, as in the $m d x / m T R$ model [16].

In this study, we aimed to accelerate and worsen the heart pathology in $m d x$ mice, through exercise, avoiding additional genetic modifications. Unlike voluntary exercise, which has been found by some [17-19] but not all studies [20,21] to be beneficial, we reasoned that forced exercise might accelerate the $m d x$ heart pathology. Indeed, "forced" running exercise on either a treadmill or by swimming is largely employed as a protocol to worsen the $m d x$ phenotype and/or to evaluate the efficacy of therapeutic interventions with pharmacotherapies [22-27]. However, most of the studies have been conducted to evaluate worsening in skeletal muscle phenotype, while only a few of them have evaluated effectiveness in accelerating the heart pathology in young $m d x$ mice [28-34]. Exercised $m d x$ hearts are characterized by increased transcription of pro-fibrotic factors such as TGF $\beta$ [31], activation of p38 MAPK, JNK1, ERK1/2, or calcineurin signaling [29], and increased cardiac fibrosis [32] or worsened heart function [34]. However, a detailed investigation of the dystrophic $m d x$ heart phenotype following exercise, including histo-pathological and functional features, as well as inflammation, is lacking.

Taking into account the protocols described previously, we hypothesized that moderate but long-lasting physical exercise might be the most effective approach for worsening heart phenotype and function in $m d x$ mice, avoiding extensive damage to skeletal muscle. Here, we demonstrate that treadmill long-term "endurance" exercise protocol accelerates $m d x$ heart fibrosis, increases inflammation, and reduces $m d x$ heart function. To the best of our knowledge, ours is the first study to investigate the effect of exercise on cardiac immune infiltration and ventricular fibrosis, both of which are key features of human DMD-related cardiomyopathy. Based on the histo-pathological features observed, this protocol could be a useful tool to study DMD-related cardiomyopathy treatments.

\section{Materials and Methods}

Mice: C57BL/10ScSn-Dm $d^{m d x}$ mice were purchased from the Jackson Laboratory (Bar Harbor, ME, USA). The mice were housed in the Histology Department-accredited animal facility at the University of Sapienza. All the procedures were approved by the Italian Ministry for Health and were conducted according to the EU regulations and the Italian Law on Animal Research. Only males were used.

Histology: Heart ventricles were embedded in tissue-freezing medium after dissection (O.C.T. Compound, Sakura, 4583) and snap-frozen in liquid nitrogen-cooled isopentane. Frozen heart ventricles were cut into $8 \mu \mathrm{m}$ sections and stored at $-20{ }^{\circ} \mathrm{C}$ until use. Histochemistry and immunofluorescence analyses were performed as previously 
described [35,36]. Briefly, for histological analysis, the sections were stained with hematoxylin/eosin or with Sirius red/picric acid (both from Sigma-Aldrich, St. Louis, MO, USA). Quantification of collagen deposition was determined using the Color Deconvolution plugin (by G. Landini) of ImageJ software. For immunostaining, permeabilization in methanol $\left(6 \mathrm{~min}\right.$ at $\left.-20^{\circ} \mathrm{C}\right)$ was performed on cryosections after fixation. Sections were incubated with anti-mouse IgG antibody coupled to Alexa Fluor 488 (Life Technologies, Carlsbad, CA, USA). Nuclei were counterstained with Hoechst 33,342 (Fluka, Charlotte, NC, USA). The sections were photographed in a Zeiss Axioskop 2 Plusfluorescence Microscope and the images were analyzed using Image J software.

Flow Cytometry: Cytofluorimetric analysis was performed as previously described $[37,38]$. Briefly, hearts were collected and cut into small pieces with a blade, and then incubated with collagenase type IV for $1 \mathrm{~h}$ and $30^{\prime}$ at $37^{\circ} \mathrm{C}$ with agitation. The obtained cell suspension was passed through a $70 \mu \mathrm{m}$ and then a $40 \mu \mathrm{m}$ cell strainer; the cells were then counted on a hemocytometer, collected by centrifugation at $1200 \mathrm{rpm}$, and suspended in $200 \mu \mathrm{L}$ of calcium/magnesium-free PBS (phosphate buffered saline) with $2 \%$ FBS (foetal bovine serum). They were then divided in two tubes for the staining. The cells were incubated on ice for $30 \mathrm{~min}$ with the following antibodies: CD45 PE/Cy7, F4/80 APC, Ly6g PE Fluor 610, CD11b APC/Cy7, CD206 PERCP/Cy5.5 Ly6c BV-510, I-Ab FITC (tube 1) and CD45 PE/Cy7, CD3 PERCP Cy5.5, B220 BV-510, CD4 AF488, and CD8 PE (tube 2), all by Biolegend, San Diego, CA, USA). Cells were then washed with $3 \mathrm{~mL}$ of calcium/magnesium-free PBS and resuspended in $200 \mu \mathrm{L}$ of calcium/magnesium-free PBS with 2\% FBS. Samples were acquired with a CyAn ADP (Agilent DAKO, Santa Clara, CA, USA), and acquired data were analyzed using FlowJo software version 10.

qRT-PCR: Total RNA from muscle tissues was extracted using the TRIsure solution (Bioline, London, UK) and converted in cDNA using the SensiFast cDNA Synthesis kit from Bioline, according to supplier's instructions. PCR amplification was performed using the SensiMix SYBR Lo-Rox Mix, from Bioline, following the manufacturer's protocol. All PCR reactions were carried out in duplicate. All qPCR results are expressed as relative ratios of the target cDNA transcripts to GAPDH and normalized to those of the reference condition. To amplify the genes of interest, we used the following primers pairs: GAPDH (for) 5'-ACCCAGAAGACTGTGGATGG-3' (rev) 5'CACATTGGGGGTAGGAACAC-3': Collagen $1 \alpha$ (for) $5^{\prime}$-ACCCAGAAGACTGTGGATGG$3^{\prime}$ (rev) 5'-CAGATTGGGGGTAGGAACAC-3', CTGF (for) 5'-AGAACTGTGTACGGAGCGTG-3' (rev) 5'-AGAACTGTGTACGGAGCGTG-3'; TGF $\beta$ (for) 5'-CCCGAAGCGGACTACTATGC-3 (rev) 5'-CATAGATGGCGTTGTTGCGG-3' .

Treadmill Exercise: The exercise was carried out using a five-lane motorized treadmill (LE 8710, PanLab S.L.U., Barcelona, Spain) supplied with shocker plates. To set up the exercise protocol, we followed the general indication contained in the S.O.P. DMD_M_2.1.001 by De Luca et al., 2008. After $10 \mathrm{~min}$ of acclimation on the stationary treadmill, the exercise started with 10 min-long «warm-up» session, in order not to stress or exhaust the mice too fast. Warm-up started at a speed of $10 \mathrm{~cm} / \mathrm{s}$, with an increase of $2 \mathrm{~cm} / \mathrm{s}$ every $2 \mathrm{~min}$. Then, $50 \mathrm{~min}$ of exercise was performed at a constant speed of $20 \mathrm{~cm} / \mathrm{s}$. We recommend spacing out two sessions of $25 \mathrm{~min}$ of exercise $(20 \mathrm{~cm} / \mathrm{s})$ with a $5 \mathrm{~min}$-long pause. An important adjustment we followed was not to use electric shocker plates to induce the mice to the run, instead using gentle manipulation or a physical obstacle. This adjustment reduced stress in mice and sensibly increased their ability to complete the exercise session, avoiding exhaustion.

Echocardiography: Echocardiographic analyses were performed as previously described $[39,40]$. Mice were anesthetized with $2.5 \%$ avertin (Sigma, St. Louis, MO, USA, T48402) to perform echocardiographic functional analyses of the fractional shortening of the left ventricle. Echocardiography was performed in M mode using a VEVO 3100 (Visualsonics, Toronto, ON, Canada) with a mx550d probe.

Statistical Analysis: All statistical analyses were performed using Prism software, version 6 (GraphPad Software, Inc., La Jolla, CA, USA). Data are presented as mean $\pm \mathrm{SEM}$. 
Unpaired two-tailed Student's $t$-test was used for statistical comparison between two groups, and one-way ANOVA (with Bonferroni correction for multiple comparisons) was used for comparisons between multiple groups. A $p$ value of $\leq 0.05$ was considered statistically significant.

\section{Results}

\subsection{Mdx Mice Display Late Onset Heart Fibrosis}

To examine the kinetics and features of dystrophic heart in $m d x$ mice, we analyzed the progression of ventricular fibrosis in 1-, 3-, 6-, and 11-month-old mdx mice, compared to age-matched wild-type mice. The extent of ventricular fibrosis was evaluated by Sirius red staining of heart cryosections and analyzed using ImageJ software. As expected, heart fibrosis starts to become evident at around 11 months of age, which is quite late, considering that the average lifespan of a mouse is 26/28 months [10] (Figure 1A,B). Since fibrosis might result from previous necrosis and sustained inflammation $[37,38]$, we analyzed the kinetics of immune cells infiltrating the $m d x$ heart. Our gating strategy is shown in Supplementary Figure S1. Non-muscular mononuclear cells were isolated from hearts derived from $m d x$ mice at 1, 3, 6, and 11 months of age, as above. Hematopoietic-infiltrating cells were identified by flow cytometry as CD45+ cells. Interestingly, we found that immune cells infiltrated the $m d x$ heart in two distinct waves; a first one around 1 month of age and the second around 11 months of age, when fibrosis is established (Figure 1C,D). Both myeloid cells (CD45+/CD11b+ cells) and T cells (CD45+/CD3+ cells) followed the same two-wave kinetics (Supplementary Figure S2).

\subsection{The Exercise Protocol Accelerates Fibrosis Onset in Mdx Heart}

In order to generate a reliable mouse model to study DMD-related cardiomyopathy, we tested the efficacy of physical exercise in accelerating $m d x$ heart pathology. Following the established SOPs included in the TREAT-NMD [41], we designed a moderate, longlasting exercise protocol, as described in Figure 2. Briefly, 4-week-old mice were subjected to a $1 \mathrm{~h}$-long running session on a treadmill at a moderate speed, twice a week for 8 weeks, up to three months of age.

To examine the effect of our exercise protocol on heart fibrosis, cryosections of the heart ventricles were stained with Sirius red, and the extent of collagen deposition was determined using ImageJ software. As shown in Figure 3, no fibrotic tissue was observed within the heart of wild-type or 3-month-old $m d x$ mice, used as controls, whereas ventricular fibrosis was evident in the heart of exercised $m d x$ mice. Interestingly, the percentage of fibrotic ventricular area in exercised $m d x$ mice was very similar to that observed in older (11-month-old) unexercised $m d x$ (Supplementary Figure S3). In agreement with the histological data, qRT-PCR showed that the level of expression of both collagen $1 \alpha 1$ and connective tissue growth factor (CTGF) mRNA, associated with cardiac fibrosis development [42], was significantly higher in the heart of exercised $m d x$ mice compared to controls, together with a slight increase in TGF- $\beta$ transcript (Figure $3 C$ ). Interestingly, tibialis anterior fibrosis was only moderately increased by the exercise protocol, and the diaphragm showed almost no change when comparing unexercised and exercised $m d x$ (Supplementary Figure S4). Overall, these results demonstrate that endurance exercise accelerates fibrotic tissue deposition in the dystrophic heart.

\subsection{The Exercised Mdx Mice Display Increased Cardiomyocyte Necrosis and Cell Infiltration}

To assess cardiac muscle organization, heart ventricles cryosections were stained with hematoxylin and eosin (H\&E). We found no obvious alterations in cardiac muscle tissue organization in exercised $m d x$ compared with age-matched wild-type or $m d x$ mice; however, a slight increase in cell infiltration area was observed, although this increase did not reach statistical significance (Figure 4A,B). Interestingly, cell infiltration patches were both higher in number and bigger in size in the heart of exercised $m d x$ mice compared to unexercised controls (Figure 4C,D). Immune cell infiltration of the dystrophic heart is often 
triggered by the necrotic cell death of cardiomyocytes [43], and fibrotic tissue deposition usually follows muscle cell death in both dystrophic skeletal and cardiac muscle [44]. We therefore analyzed cardiomyocyte necrosis after the exercise protocol. Interestingly, there was a significant increase in the ventricular necrotic area in exercised $m d x$ heart compared to unexercised controls, as shown by immunofluorescence analysis using an anti-mouse IgG antibody (Figure 4E,F). Taken together, these results demonstrate that the exercise protocol worsens the dystrophic heart phenotype in terms of increased cell infiltration and cardiomyocytes necrosis.

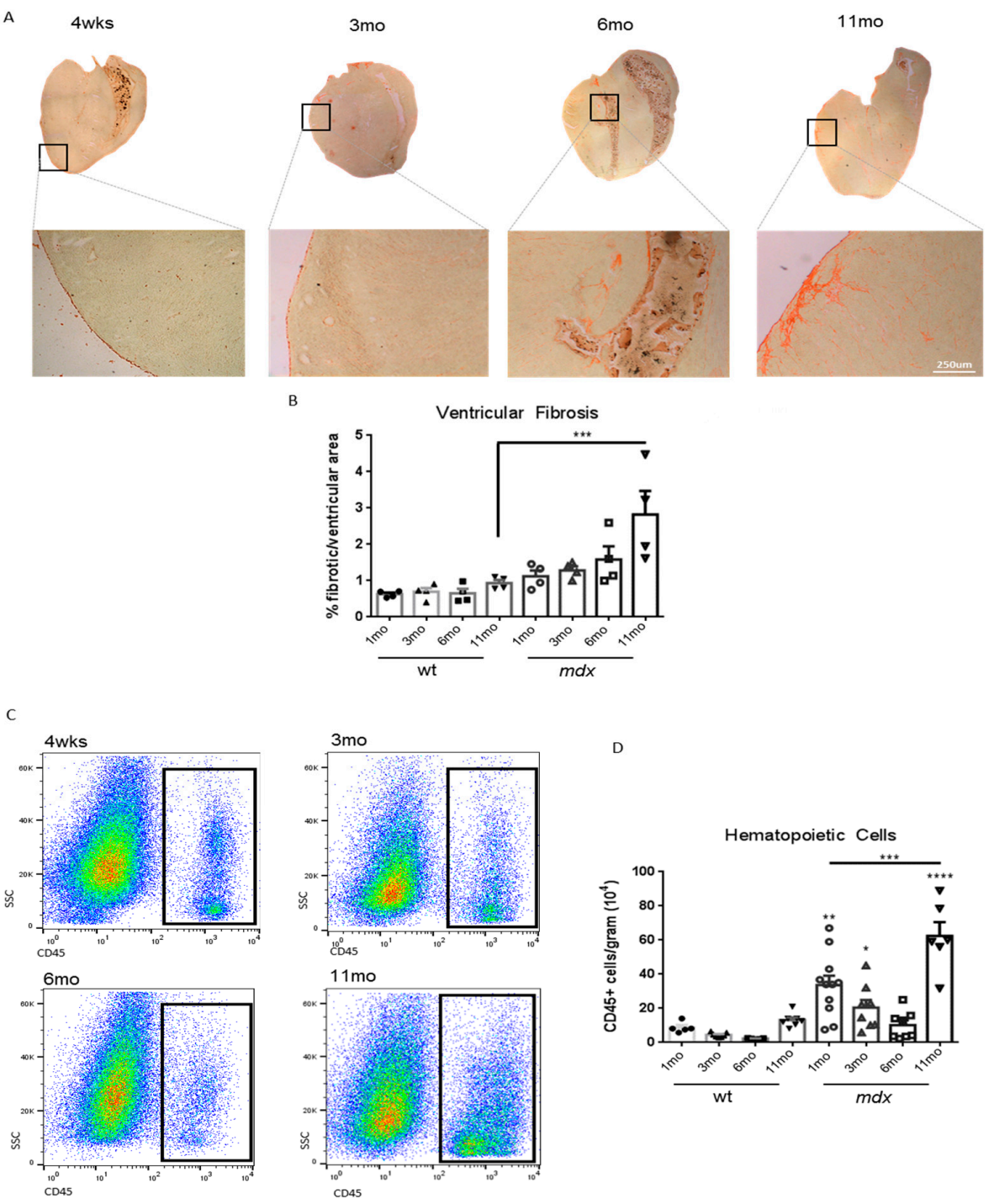

Figure 1. Kinetics of fibrosis establishment and immune infiltration in $m d x$ hearts: (A) representative images of Sirius red collagen staining of heart ventricles cryosections from $m d x$ mice of 1, 3, 6, and 11 months of age. (B) Quantification of ventricular fibrotic area, determined as in (A), expressed as percentage over total area, calculated with ImageJ Color Deconvolution plugin. $n=4$ independent samples. The level of ventricular fibrotic area determined in age-matched wild-type mice, as in (A), is also shown. (C) Representative images of cytofluorimetric analysis of cells derived from $m d x$ mice hearts of $1,3,6$, and 11 months of age, showing the gating for CD45+ cells, as determined after excluding debris, doublets, and dead cells. (D) Quantification of the CD45+ cells infiltrating wild-type or $m d x$ heart at the indicated ages, expressed as number per gram of tissue. $n=5-11$ independent samples. Data are shown as mean \pm S.E.M; ${ }^{*}=p<0.05,{ }^{* *}=p>0.01,{ }^{* * *}=p<0.001$, $* * * *=p<0.0001$, ordinary one-way ANOVA with Bonferroni correction for multiple comparisons. 
A

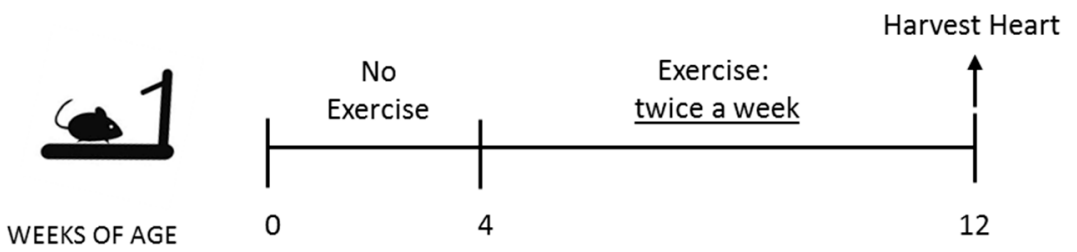

B

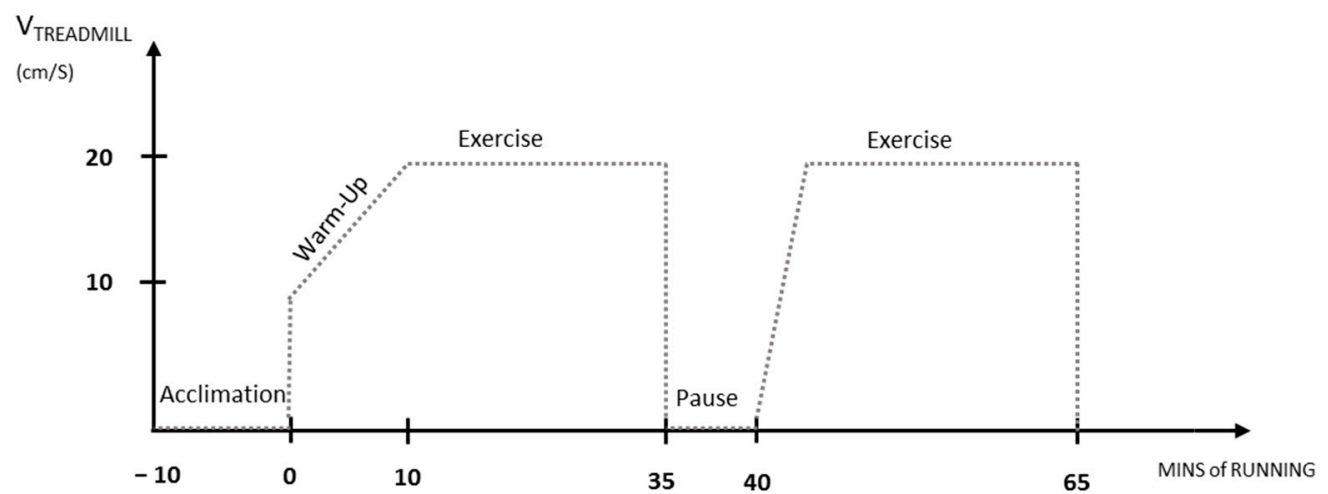

Figure 2. Description of the exercise protocol: (A) timeline of the exercise protocol: 4-week-old mice were exercised twice a week for 2 months. (B) Description of the exercise session: mice were exercised on the treadmill with no inclination. Each session consists in $1 \mathrm{~h}$ of running at moderate speed (max $20 \mathrm{~cm} / \mathrm{s}$ ). After $10 \mathrm{~min}$ of acclimation on the stationary treadmill, the exercise starts with 10 min-long «warm-up» session, when the speed is slowly increased from $10 \mathrm{~cm} / \mathrm{s}$ to $20 \mathrm{~cm} / \mathrm{s}$. Two session of exercise at a constant speed of $20 \mathrm{~cm} / \mathrm{s}$ are spaced out by a 5 min-long pause. Instead of shocker plates, gentle manipulation or physical obstacles are used to force running.

\subsection{Inflammatory Cell Infiltration Is Increased in the Exercised Mdx Heart}

Most fibrotic disorders are characterized by persistent inflammation, leading to the production of growth factors, proteolytic enzymes, and pro-fibrotic cytokines, which stimulate the deposition of fibrotic tissue $[43,44]$. Since we observed an increase in heart fibrosis, necrosis, and ventricular infiltration area, we then analyzed the level and the type of inflammatory cells infiltrating the heart of exercised $m d x$ mice by cytofluorimetric analysis. We found that total CD45+ hematopoietic cells were increased in the heart of exercised $m d x$ mice compared to controls (Figure 5A,B). Within this cell population, the number of all immune cell subpopulations analyzed, including CD11b+ myeloid cells, CD11b+/F4/80 hi macrophages (MP), CD11b+F4/80+/Ly6chi recently recruited Mo/MP, CD11b+Ly6g+ neutrophils, and CD3+ T cells, increased in the exercised $m d x$ heart compared to the aged-matched controls (Figure 5C). The level of immune cell infiltration found in the exercised $m d x$ hearts was similar to the level observed in 11month-old $m d x$ (Supplementary Figure S5). Taken together, these results demonstrate that the exercise protocol hastens immune cell infiltration in the $m d x$ heart, worsening the histo-pathological phenotype. 
A
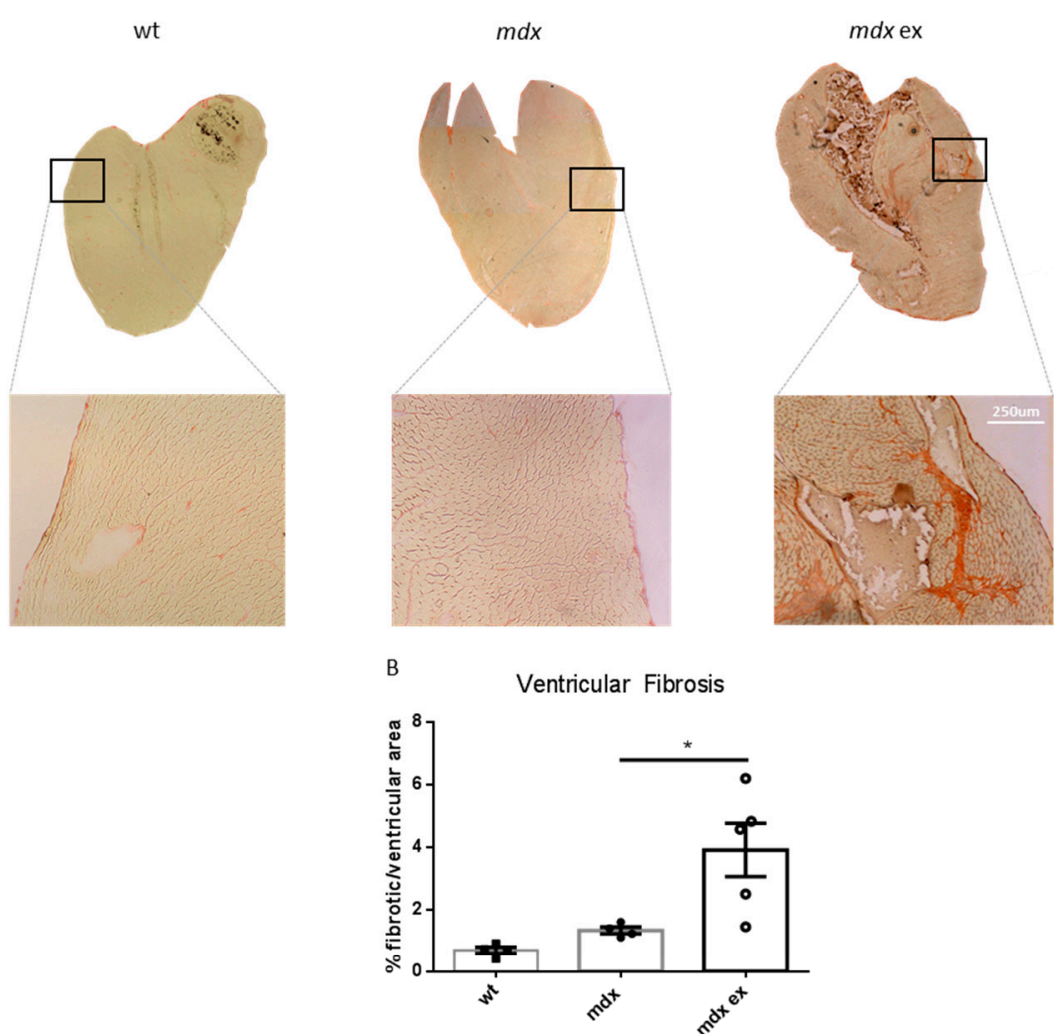

C
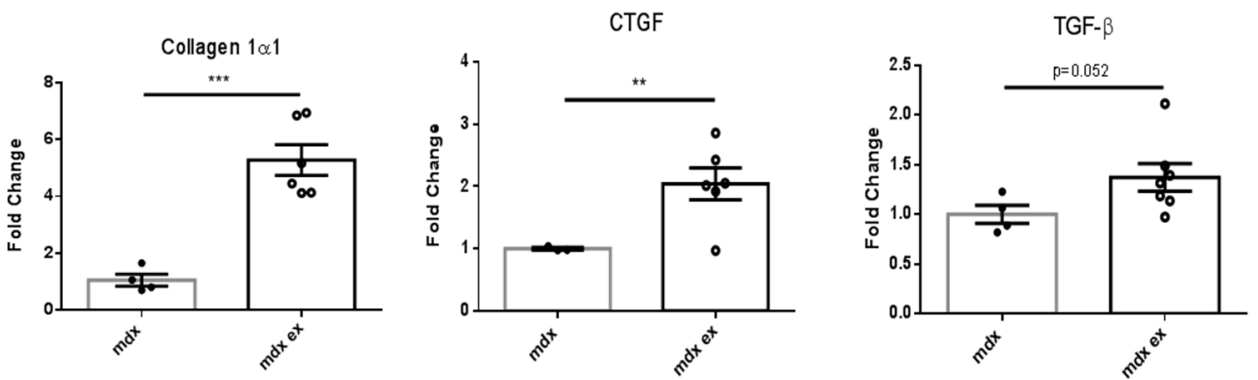

Figure 3. Increased fibrotic tissue deposition in exercised $m d x$ heart ventricles: (A) representative images of Sirius red collagen staining of heart ventricles cryosections from wild-type C57/BL10, exercised $m d x$, and control $m d x$ mice. (B) Quantification of heart ventricular fibrosis, determined by Sirius red collagen staining as in (A). Data are expressed as percentage of ventricular fibrotic area over total ventricular area, as determined with ImageJ Color Deconvolution plugin by G. Landini. $n=4-5$ independent samples/group; ${ }^{*}=p<0.05$, ordinary one-way ANOVA with Bonferroni correction for multiple comparisons. (C) qRT-PCR on total heart RNA in exercised and control $m d x$ for the pro-fibrotic factors collagen $1 \alpha 1$, connective tissue growth factor (CTGF), and TGF- $\beta$. Data expressed as fold change $\left(2^{- \text {ddCT }}\right)$ normalized with GAPDH. Data are shown as media \pm S.E.M. $n=4$, 6 independent samples; ${ }^{*}=p<0.05,{ }^{* *}=p<0.01,{ }^{* * *}=p<0.001$, unpaired $t$-test $\mathrm{w} /$ Welch's correction. 
A

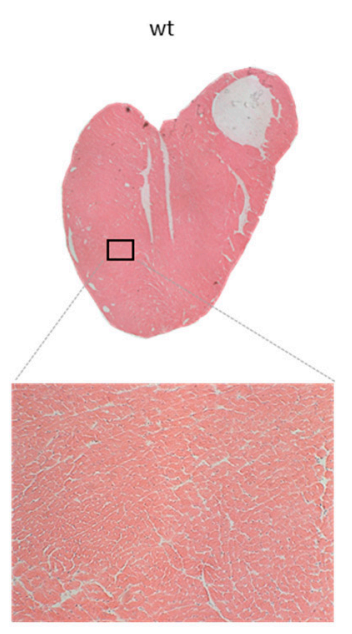

B
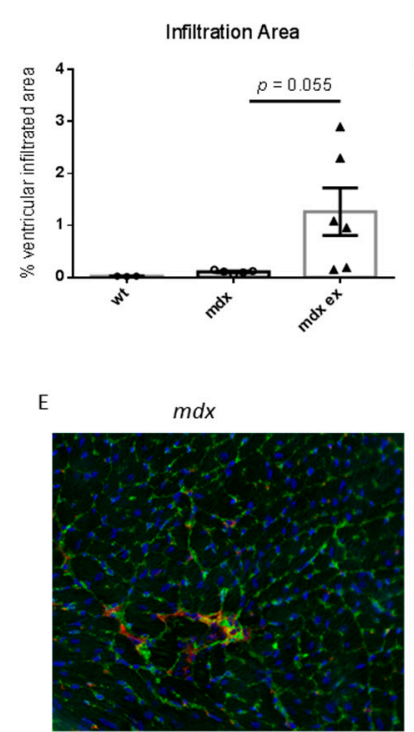
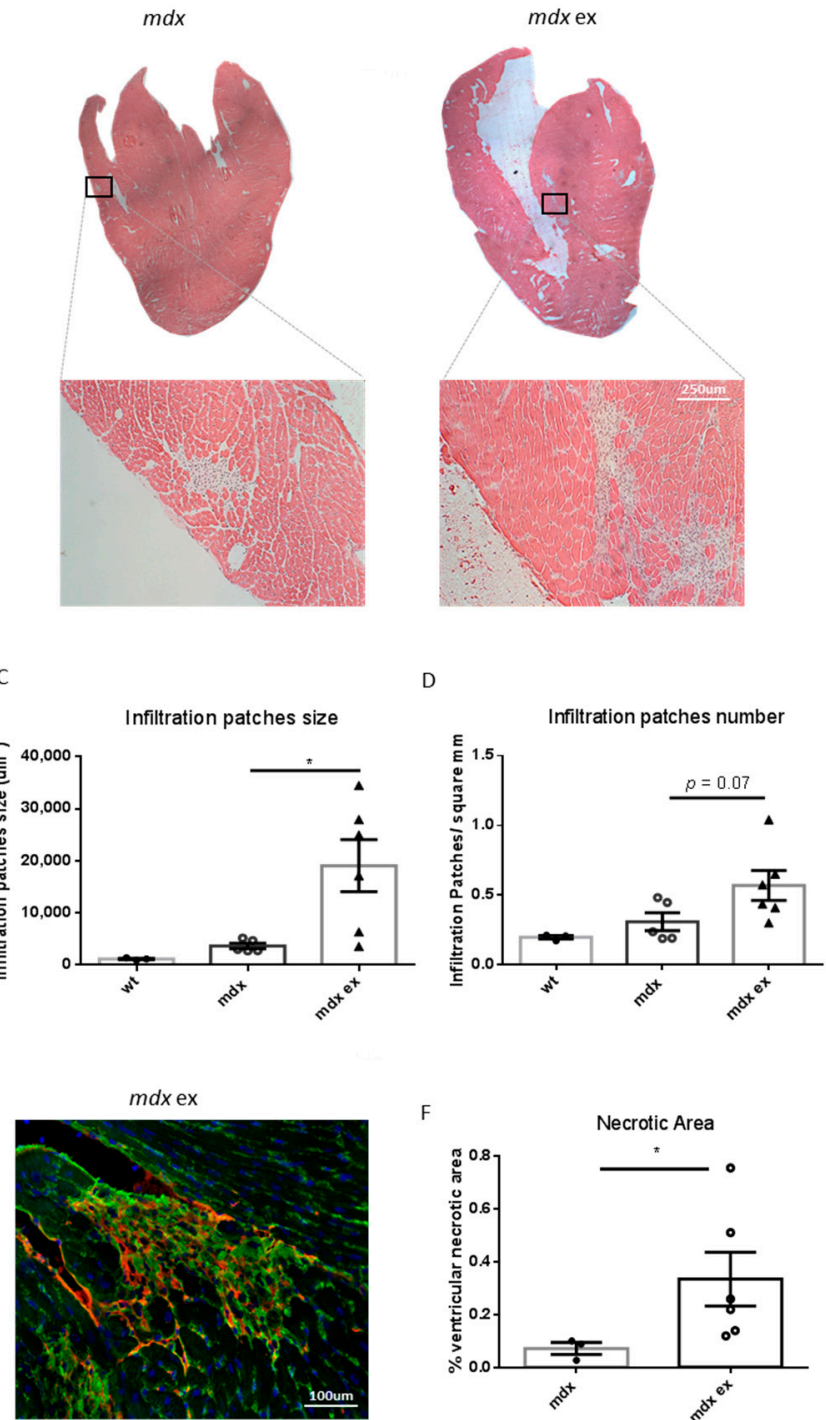

F

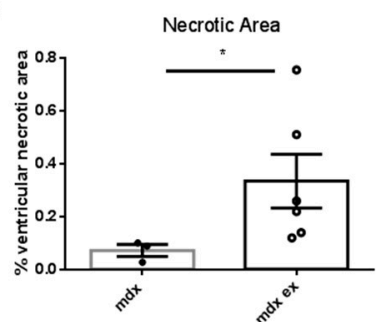

Laminin + mouse IgG + DAPI

Figure 4. Increased non-muscle cells' infiltration area and cardiomyocyte necrosis in exercised $m d x$ heart ventricles: (A) representative $H \& E$ staining of ventricular cryosections derived from wild-type, exercised, and control $m d x$. (B) Quantification of cell infiltration area expressed as percentage over total ventricular area, as determined in H\&E stained cryosections. (C) Quantification of the size of cell infiltration patches, expressed in $\mu \mathrm{m}^{2}$. (D) Quantification of the number of cell infiltration patches, normalized per $\mathrm{mm}^{2}$. Data from B, C, and D are shown as mean \pm S.E.M., $n=3-6$ independent samples/group; ${ }^{*}=p<0.05$, ordinary one-way ANOVA with Bonferroni correction for multiple comparisons. All quantifications were calculated using ImageJ software. (E) Representative images of immunofluorescence of ventricular cryosection from exercised and control $m d x$ using an anti-mouse IgG antibody staining. (F) Quantification of ventricular necrotic area expressed as percentage over total ventricular area, calculated using ImageJ software. Data are shown as mean \pm S.E.M $n=3 / 6$ independent samples ${ }^{*}=p<0.05$, unpaired $t$-test $\mathrm{w} /$ Welch's correction. 


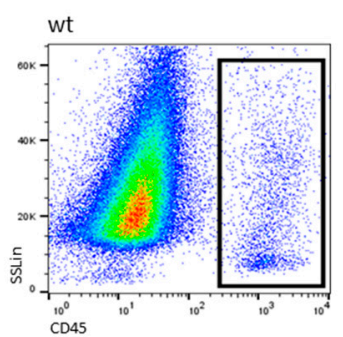

B
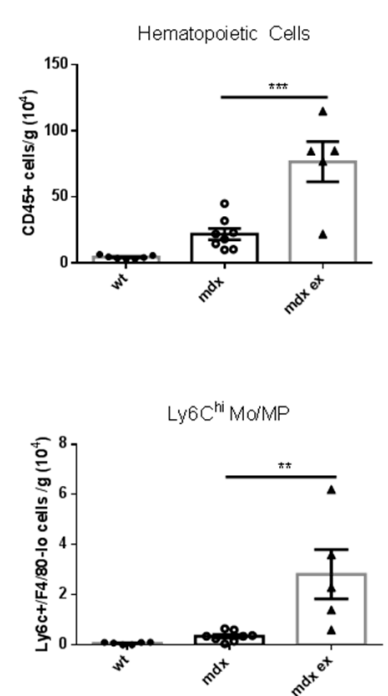
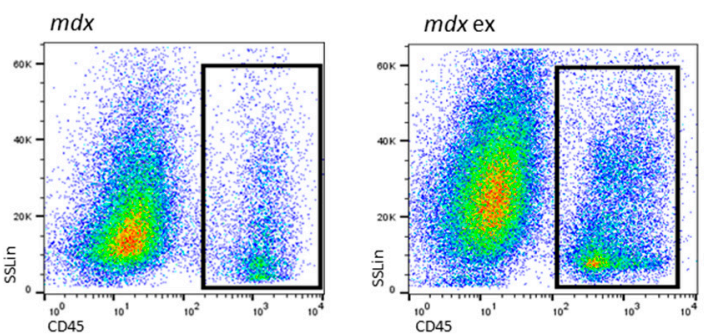

C
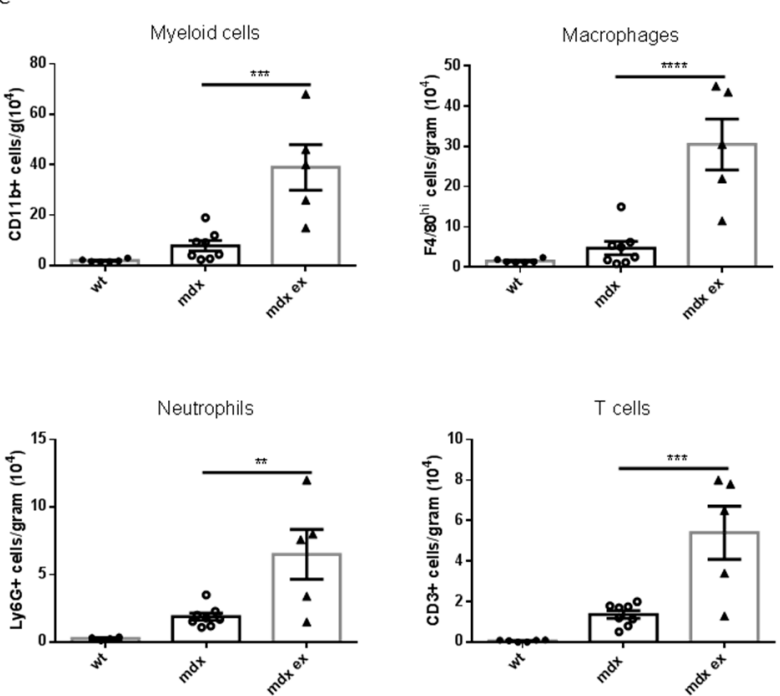

Figure 5. Cytofluorimetric analysis of the immune population isolated from wild-type, exercised $m d x$, and control $m d x$ hearts: (A) representative images showing the gating for CD45+ infiltrating cells in wild-type exercised and control $m d x$ hearts, after excluding debris, doublets, and dead cells. (B) Quantification of total hematopoietic cells infiltrating wild-type, exercised $m d x$, and control $m d x$ hearts, identified as CD45 positive and expressed as number of cells normalized per gram of tissue. (C) Quantification of the immune subpopulation infiltrating the heart of wild-type, exercised $m d x$, and control $m d x$ mice, expressed as number of cells normalized per gram of tissue. The cell populations were identified as indicated: total myeloid cells as CD11b+, macrophages as Ly6c-/F4/80 hi , freshly recruited monocytes as Ly6c ${ }^{\text {hi }} / \mathrm{F} 4 / 80-$, neutrophils as Ly6g+, and T cells as CD3+. Data are shown as mean \pm S.E.M., $n=6 / 8 / 5$ independent samples. ${ }^{* *}=p<0.01,{ }^{* * *}=p<0.01,{ }^{* * * *}=p<0.0001$, ordinary one-way ANOVA with Bonferroni correction for multiple comparisons.

\subsection{The Exercise Protocol Alters Mdx Heart Function}

In DMD-related cardiomyopathy progression, fibrotic tissue deposition is associated with ventricular hypertrophy, and is followed by progressive left ventricle dysfunction, reduced heart contractility, and ejection volume. To determine whether the exercise protocol might lead to an alteration in heart function, we performed echocardiographic analysis in exercised and control $m d x$ mice. There were no evident alterations in the dilation of the chambers, heart/body weight ratio, wall thickness, or heart rate (Table 1). However, as shown in Figure 6, the left ventricle fractional shortening in the heart of exercised $m d x$ mice was significantly reduced compared with the age-matched controls. These results demonstrate that the increased cardiac fibrosis induced by exercise in $m d x$ mice has a direct and measurable impact on heart function. 
Table 1. Summary of the main echocardiographic parameters in exercised and control $m d x$. Data are expressed as mean \pm S.E.M., $n=6 / 7$ independent samples. ${ }^{*}=p<0.05$.

\begin{tabular}{cccccccc}
\hline & $\begin{array}{c}\text { End-Diastolic } \\
\text { Diameter } \\
{[\mathbf{m m}]}\end{array}$ & $\begin{array}{c}\text { End-Systolic } \\
\text { Diameter } \\
{[\mathbf{m m}]}\end{array}$ & $\begin{array}{c}\text { Anterior Wall } \\
\text { Thickness } \\
{[\mathbf{m m}]}\end{array}$ & $\begin{array}{c}\text { Posterior Wall } \\
\text { Thickness } \\
{[\mathbf{m m}]}\end{array}$ & $\begin{array}{c}\text { Fractional } \\
\text { Shortening } \\
{[\%]}\end{array}$ & $\begin{array}{c}\text { Heart Rate } \\
\mathbf{( b p m )}\end{array}$ & $\begin{array}{c}\text { Heart/Body } \\
\text { Weight [mg/g] }\end{array}$ \\
\hline$m d x$ & $2.77 \pm 0.07$ & $1.27 \pm 0.08$ & $1.13 \pm 0.04$ & $1.08 \pm 0.02$ & $* 54.42 \pm 1.89$ & $452 \pm 25.2$ & $7.0 \pm 0.24$ \\
$m d x$ ex & $2.76 \pm 0.06$ & $1.44 \pm 0.03$ & $1.06 \pm 0.04$ & $1.11 \pm 0.03$ & $* 48.14 \pm 1.61$ & $443 \pm 43.8$ & $6.8 \pm 0.17$ \\
\hline
\end{tabular}

A

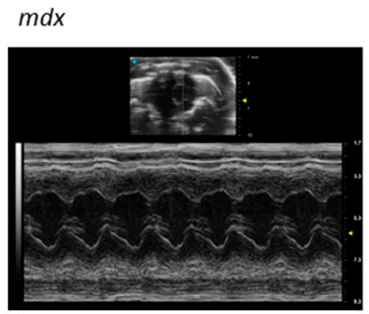

$m d x$ ex

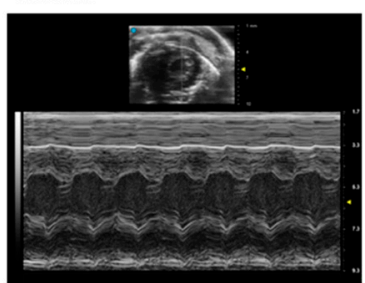

B

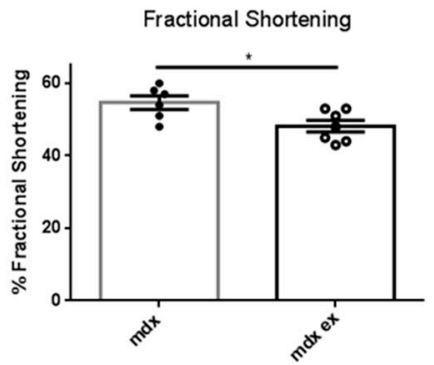

Figure 6. Echocardiographic analysis of left ventricle fractional shortening in exercised and control $m d x$ : (A) representative images of the echocardiographic analysis of exercised and control $m d x$ hearts, as indicated. (B) Left ventricle fractional shortening expressed as percentage and calculated on the short axe. Data are shown as mean \pm S.E.M., $n=6 / 7$ independent samples; ${ }^{*}=p<0.05$, unpaired $t$-test $\mathrm{w} /$ Welch's correction.

\section{Discussion}

This study demonstrates that long-term endurance exercise in $m d x$ mice hastens the histo-pathological features of $m d x$ dystrophic heart, in terms of fibrosis, inflammation, and function, making it a reliable model to test future therapeutic strategies. Indeed, one of the major stumbling blocks in developing such a strategy has been the absence of animal models mirroring the severity of the heart pathology seen in humans. The dystrophic pathology progression in the heart of the widely used model of DMD, the $m d x$ mouse, is slower and milder in comparison to that of human patients [45].

As expected, we found that the extent of heart fibrosis in $m d x$ mice increased with increasing age, and coincided with a peak of infiltrating immune cell, suggesting that fibrosis is driven by the inflammatory response. Interestingly, an earlier peak of immune cells' infiltration was observed in the heart of 1-month-old $m d x$ mice, at the age when skeletal muscle necrosis is very high $[37,38]$. Although not proven yet, we believe that this early peak depends on a systemic immune response, due to skeletal muscle damage, while the later one might represent a cardiac-specific response.

Although many papers investigated the effect of physical exercise on $m d x$ skeletal muscle, only few of them assessed the impact of exercise on the heart. Physical exercise has been previously shown to activate p38 MAPK, JNK1, ERK1/2, or calcineurin signaling in $m d x$ cardiac muscle [29], increase heart fibrosis [32], or impair heart function [34]. However, no detailed analysis of the inflammatory response and heart fibrosis has been conducted previously.

We found that our exercise protocol induced heart fibrosis in 3-mont-old $m d x$ mice, at an age when no heart defects are detectable yet, and at a level comparable to that observed in 11-month-old mice. Interestingly, similar exercise protocols (i.e., chronic, moderate-intensity exercise) were described as beneficial for cardiac features in wild mice instead [46-50], suggesting that the effects we see in the heart of exercised $m d x$ depend on altered susceptibility to work demand, due to a lack of dystrophin. Accordingly, cardiomyocyte necrosis and immune cells' infiltration was observed in the heart of exercised $m d x$ mice, also at levels comparable to those seen in 11-month-old $m d x$ mice. These results suggest that endurance exercise leads to early cardiac fibrosis driven by necrosis-induced inflammatory response. Importantly, we show that the exercise-induced heart fibrosis 
impairs heart function, as the left ventricle fractional shortening significantly decreased in 3month-old exercised $m d x$ mice compared to controls. Indeed, the level of reduced fractional shortening is consistent with the level of fibrotic deposition observed [51]. Although it might appear mild, this decrease is meaningful in terms of prognosis, as it might be predictive of a late-onset and more pronounced left ventricular dysfunction.

To the best of our knowledge, this is the first study to characterize the histo-pathological phenotype of the heart in $m d x$ mice upon exercise, analyzing all the key features of the dystrophic heart: immune cells infiltration, cardiomyocyte necrosis, ventricular fibrosis, and impaired function. We show that endurance, forced, and long-lasting exercise worsens the $m d x$ heart phenotype, accelerating the progression of dystrophic cardiomyopathy without adversely affecting the diaphragm, and with only a moderate impact on limb muscle fibrosis. Although the level of heart damage is still not as severe as in the human disease, we believe that this protocol represents a fast, cheap, and easily reproducible way to worsen the $m d x$ heart phenotype in order to evaluate the potential of novel therapeutic approaches aimed at ameliorating dystrophic heart pathology.

Supplementary Materials: The following are available online at https://www.mdpi.com/article/ 10.3390/life11070706/s1, Figure S1: Cytofluorimetric Gating Strategy; Figure S2: Quantification of immune cells populations in exercised and old $\mathrm{mdx}$ heart; Figure S3: Ventricular fibrosis in old and exercised mdx; Figure S4: Skeletal muscle is partially affected by the exercise protocol; Figure S5: Quantification of the immune population infiltrating exercised and control mdx mice.

Author Contributions: Conceptualization, J.M., L.S., S.S., B.L.-O. and M.B.; validation, J.M., L.S.; 332 formal analysis, J.M., L.S.; investigation, J.M., C.N., L.S., V.V., D.V., L.D.; resources, S.S., M.B.; data 333 curation, J.M., L.S., S.S., B.L.-O. and M.B.; writing-original draft preparation, J.M.; writing-review 334 and editing, J.M., L.S., B.L.-O., S.S., M.B., supervision, S.S., B.L.-O. and M.B.; funding acquisition, M.B. All authors have read and agreed to the published version of the manuscript.

Funding: This research was funded by Duchenne Parent Project, Italy and Sapienza University of Rome (grants number: RP120172B32DE4C7 and RP11715C7D238352) to MB.

Institutional Review Board Statement: All the procedures were approved by the Italian Ministry for Health and were con-ducted according to the EU regulations and the Italian Law on Animal Research. (Authorization \#60/2018 released on 29 January 2018 from the Ministry of Health).

Informed Consent Statement: Not applicable.

Data Availability Statement: No new data were created or analyzed in this study. Data sharing is not applicable to this article.

Acknowledgments: The authors would like to thank Fabrizio Padula (DAHFMO, Sapienza University of Rome) for his technical support.

Conflicts of Interest: The authors declare no conflict of interest. The funders had no role in the design of the study; in the collection, analyses, or interpretation of data; in the writing of the manuscript, or in the decision to publish the results.

\section{References}

1. Meyers, T.A.; Townsend, D.W. Cardiac pathophysiology and the future of cardiac therapies in duchenne muscular dystrophy. Int. J. Mol. Sci. 2019, 20, 4098. [CrossRef]

2. Mosqueira, M.; Zeiger, U.; Förderer, M.; Brinkmeier, H.; Fink, R.H. Cardiac and respiratory dysfunction in duchenne muscular dystrophy and the role of second messengers. Med. Res. Rev. 2013, 33, 1174-1213. [CrossRef]

3. D'Amario, D.; Gowran, A.; Canonico, F.; Castiglioni, E.; Rovina, D.; Santoro, R.; Spinelli, P.; Adorisio, R.; Amodeo, A.; Perrucci, G.; et al. Dystrophin Cardiomyopathies: Clinical Management, Molecular Pathogenesis and Evolution towards Precision Medicine. J. Clin. Med. 2018, 7, 291. [CrossRef]

4. Buddhe, S.; Cripe, L.; Friedland-Little, J.; Kertesz, N.; Eghtesady, P.; Finder, J.; Hor, K.; Judge, D.P.; Kinnett, K.; McNally, E.M.; et al. Cardiac management of the patient with Duchenne muscular dystrophy. Pediatrics 2018, 142, S72-S81. [CrossRef] [PubMed]

5. Kamdar, F.; Garry, D.J. Dystrophin-Deficient Cardiomyopathy. J. Am. Coll. Cardiol. 2016, 67, 2533-2546. [CrossRef] [PubMed]

6. Nigro, G.; Comi, L.I.; Politano, L.; Bain, R.J.I. The incidence and evolution of cardiomyopathy in Duchenne muscular dystrophy. Int. J. Cardiol. 1990, 26, 271-277. [CrossRef] 
7. McGreevy, J.W.; Hakim, C.H.; McIntosh, M.A.; Duan, D. Animal models of Duchenne muscular dystrophy: From basic mechanisms to gene therapy. DMM Dis. Model. Mech. 2015, 8, 195-213. [CrossRef]

8. Wilson, K.; Faelan, C.; Patterson-Kane, J.C.; Rudmann, D.G.; Moore, S.A.; Frank, D.; Charleston, J.; Tinsley, J.; Young, G.D.; Milici, A.J. Duchenne and Becker Muscular Dystrophies: A Review of Animal Models, Clinical End Points, and Biomarker Quantification. Toxicol. Pathol. 2017, 45, 961-976. [CrossRef] [PubMed]

9. Partridge, T.A. The mdx mouse model as a surrogate for Duchenne muscular dystrophy. FEBS J. 2013, 280, 4177-4186. [CrossRef]

10. Chamberlain, J.S.; Metzger, J.; Reyes, M.; Townsend, D.; Faulkner, J.A. Dystrophin-deficient mdx mice display a reduced life span and are susceptible to spontaneous rhabdomyosarcoma. FASEB J. 2007, 21, 2195-2204. [CrossRef]

11. Landfeldt, E.; Thompson, R.; Sejersen, T.; McMillan, H.J.; Kirschner, J.; Lochmüller, H. Life expectancy at birth in Duchenne muscular dystrophy: A systematic review and meta-analysis. Eur. J. Epidemiol. 2020, 35, 643-653. [CrossRef]

12. Eagle, M.; Baudouin, S.V.; Chandler, C.; Giddings, D.R.; Bullock, R.; Bushby, K. Survival in Duchenne muscular dystrophy: Improvements in life expectancy since 1967 and the impact of home nocturnal ventilation. Neuromuscul. Disord. 2002, 12, 926-929. [CrossRef]

13. Isaac, C.; Wright, A.; Usas, A.; Li, H.; Tang, Y.; Mu, X.; Greco, N.; Dong, Q.; Vo, N.; Kang, J.; et al. Dystrophin and utrophin "double knockout" dystrophic mice exhibit a spectrum of degenerative musculoskeletal abnormalities. J. Orthop. Res. 2013, 31, 343-349. [CrossRef] [PubMed]

14. Voit, A.; Patel, V.; Pachon, R.; Shah, V.; Bakhutma, M.; Kohlbrenner, E.; McArdle, J.J.; Dell'Italia, L.J.; Mendell, J.R.; Xie, L.H.; et al. Reducing sarcolipin expression mitigates Duchenne muscular dystrophy and associated cardiomyopathy in mice. Nat. Commun. 2017, 8, 1068. [CrossRef] [PubMed]

15. Howard, Z.M.; Dorn, L.E.; Lowe, J.; Gertzen, M.D.; Ciccone, P.; Rastogi, N.; Odom, G.L.; Accornero, F.; Chamberlain, J.S.; Rafael-Fortney, J.A. Micro-dystrophin gene therapy prevents heart failure in an improved Duchenne muscular dystrophy cardiomyopathy mouse model. JCI Insight 2021, 6, e146511. [CrossRef] [PubMed]

16. Sacco, A.; Mourkioti, F.; Tran, R.; Choi, J.; Llewellyn, M.; Kraft, P.; Shkreli, M.; Delp, S.; Pomerantz, J.H.; Artandi, S.E.; et al. Short telomeres and stem cell exhaustion model duchenne muscular dystrophy in mdx/mTR mice. Cell 2010, 143, 1059-1071. [CrossRef] [PubMed]

17. Selsby, J.T.; Acosta, P.; Sleeper, M.M.; Barton, E.R.; Sweeney, H.L. Long-term wheel running compromises diaphragm function but improves cardiac and plantarflexor function in the mdx mouse. J. Appl. Physiol. 2013, 115, 660-666. [CrossRef]

18. Baltgalvis, K.A.; Call, J.A.; Cochrane, G.D.; Laker, R.C.; Yan, Z.; Lowe, D.A. Exercise training improves plantar flexor muscle function in mdx Mice. Med. Sci. Sports Exerc. 2012, 44, 1671-1679. [CrossRef] [PubMed]

19. Kogelman, B.; Putker, K.; Hulsker, M.; Tanganyika-de Winter, C.; van der Weerd, L.; Aartsma-Rus, A.; van Putten, M. Voluntary exercise improves muscle function and does not exacerbate muscle and heart pathology in aged Duchenne muscular dystrophy mice. J. Mol. Cell. Cardiol. 2018, 125, 29-38. [CrossRef]

20. Hourdé, C.; Joanne, P.; Medja, F.; Mougenot, N.; Jacquet, A.; Mouisel, E.; Pannerec, A.; Hatem, S.; Butler-Browne, G.; Agbulut, O.; et al. Voluntary physical activity protects from susceptibility to skeletal muscle contraction-induced injury but worsens heart function in mdx mice. Am. J. Pathol. 2013, 182, 1509-1518. [CrossRef]

21. Costas, J.M.; Nye, D.J.; Henley, J.B.; Plochocki, J.H. Voluntary exercise induces structural remodeling in the hearts of dystrophindeficient mice. Muscle Nerve 2010, 42, 881-885. [CrossRef] [PubMed]

22. Barbin, I.C.C.; Pereira, J.A.; Bersan Rovere, M.; de Oliveira Moreira, D.; Marques, M.J.; Santo Neto, H. Diaphragm degeneration and cardiac structure in mdx mouse: Potential clinical implications for Duchenne muscular dystrophy. J. Anat. 2016, 228, 784-791. [CrossRef] [PubMed]

23. Burdi, R.; Rolland, J.F.; Fraysse, B.; Litvinova, K.; Cozzoli, A.; Giannuzzi, V.; Liantonio, A.; Camerino, G.M.; Sblendorio, V.; Capogrosso, R.F.; et al. Multiple pathological events in exercised dystrophic mdx mice are targeted by pentoxifylline: Outcome of a large array of in vivo and ex vivo tests. J. Appl. Physiol. 2009, 106, 1311-1324. [CrossRef] [PubMed]

24. Sanarica, F.; Mantuano, P.; Conte, E.; Cozzoli, A.; Capogrosso, R.F.; Giustino, A.; Cutrignelli, A.; Cappellari, O.; Rolland, J.F.; De Bellis, M.; et al. Proof-of-concept validation of the mechanism of action of Src tyrosine kinase inhibitors in dystrophic mdx mouse muscle: In vivo and in vitro studies. Pharmacol. Res. 2019, 145, 1042600. [CrossRef]

25. Capogrosso, R.F.; Mantuano, P.; Cozzoli, A.; Sanarica, F.; Massari, A.M.; Conte, E.; Fonzino, A.; Giustino, A.; Rolland, J.F.; Quaranta, A.; et al. Contractile efficiency of dystrophic mdx mouse muscle: In vivo and ex vivo assessment of adaptation to exercise of functional end points. J. Appl. Physiol. 2017, 122, 828-843. [CrossRef]

26. Bouchentouf, M.; Benabdallah, B.F.; Mills, P.; Tremblay, J.P. Exercise improves the success of myoblast transplantation in mdx mice. Neuromuscul. Disord. 2006, 16, 518-529. [CrossRef]

27. da Bizario, J.C.S.; Cerri, D.G.; Rodrigues, L.C.; Oliveira, G.L.V.; Nomizo, A.; de Araujo, D.D.; Fukuhara, P.S.; Ribeiro, J.C.; de Castro, F.A.; Costa, M.C.R. Imatinib mesylate ameliorates the dystrophic phenotype in exercised mdx mice. J. Neuroimmunol. 2009, 212, 93-101. [CrossRef]

28. Hyzewicz, J.; Ruegg, U.T.; Takeda, S. Comparison of Experimental Protocols of Physical Exercise for mdx Mice and Duchenne Muscular Dystrophy Patients. J. Neuromuscul. Dis. 2015, 2, 325-342. [CrossRef]

29. Nakamura, A.; Yoshida, K.; Takeda, S.; Dohi, N.; Ikeda, S.I. Progression of dystrophic features and activation of mitogen-activated protein kinases and calcineurin by physical exercise, in hearts of mdx mice. FEBS Lett. 2002, 520, 18-24. [CrossRef] 
30. Zelikovich, A.S.; Quattrocelli, M.; Salamone, I.M.; Kuntz, N.L.; McNally, E.M. Moderate exercise improves function and increases adiponectin in the mdx mouse model of muscular dystrophy. Sci. Rep. 2019, 9, 5770. [CrossRef]

31. Taniguti, A.P.T.; Pertille, A.; Matsumura, C.Y.; Neto, H.S.; Marques, M.J. Prevention of muscle fibrosis and myonecrosis in mdxmice by suramin, a TGF- $\beta 1$ blocker. Muscle Nerve 2011, 43, 82-87. [CrossRef] [PubMed]

32. Schill, K.E.; Altenberger, A.R.; Lowe, J.; Periasamy, M.; Villamena, F.A.; Rafael-Fortney, J.A.; Devor, S.T. Muscle damage, metabolism, and oxidative stress in mdx mice: Impact of aerobic running. Muscle Nerve 2016, 54, 110-117. [CrossRef]

33. Frinchi, M.; Morici, G.; Mudó, G.; Bonsignore, M.R.; Di Liberto, V. Beneficial role of exercise in the modulation of mdx muscle plastic remodeling and oxidative stress. Antioxidants 2021, 10, 558. [CrossRef]

34. Betts, C.A.; Saleh, A.F.; Carr, C.A.; Hammond, S.M.; Coenen-Stass, A.M.L.; Godfrey, C.; McClorey, G.; Varela, M.A.; Roberts, T.C.; Clarke, K.; et al. Prevention of exercised induced cardiomyopathy following Pip-PMO treatment in dystrophic mdx mice. Sci. Rep. 2015, 5, 8986. [CrossRef] [PubMed]

35. Fiore, P.F.; Benedetti, A.; Sandonà, M.; Madaro, L.; De Bardi, M.; Saccone, V.; Puri, P.L.; Gargioli, C.; Lozanoska-Ochser, B.; Bouché, M. Lack of PKC $\theta$ promotes regenerative ability of muscle stem cells in chronic muscle injury. Int. J. Mol. Sci. 2020, $21,932$. [CrossRef] [PubMed]

36. Paoletti, R.; Maffei, A.; Madaro, L.; Notte, A.; Stanganello, E.; Cifelli, G.; Carullo, P.; Molinaro, M.; Lembo, G.; Bouché, M. Protein kinase $\mathrm{C} \theta$ is required for cardiomyocyte survival and cardiac remodeling. Cell Death Dis. 2010, 1, e45. [CrossRef] [PubMed]

37. Rizzo, G.; Di Maggio, R.; Benedetti, A.; Morroni, J.; Bouche, M.; Lozanoska-Ochser, B. Splenic Ly6Chi monocytes are critical players in dystrophic muscle injury and repair. JCI Insight 2020, 5, e130807. [CrossRef]

38. Lozanoska-Ochser, B.; Benedetti, A.; Rizzo, G.; Marrocco, V.; Di Maggio, R.; Fiore, P.; Bouche, M. Targeting early PKC $\theta$-dependent T-cell infiltration of dystrophic muscle reduces disease severity in a mouse model of muscular dystrophy. J. Pathol. 2018, 244, 323-333. [CrossRef]

39. Sciarretta, S.; Yee, D.; Nagarajan, N.; Bianchi, F.; Saito, T.; Valenti, V.; Tong, M.; Del Re, D.P.; Vecchione, C.; Schirone, L.; et al. Trehalose-Induced Activation of Autophagy Improves Cardiac Remodeling After Myocardial Infarction. J. Am. Coll. Cardiol. 2018, 71, 1999-2010. [CrossRef]

40. Sciarretta, S.; Zhai, P.; Maejima, Y.; DelRe, D.P.; Nagarajan, N.; Yee, D.; Liu, T.; Magnuson, M.A.; Volpe, M.; Frati, G.; et al. MTORC2 regulates cardiac response to stress by inhibiting MST1. Cell Rep. 2015, 11, 125-136. [CrossRef]

41. De Luca, A. Use of Treadmill and Wheel Exercise for Impact on Mdx Mice Phenotype SOP; Wellstone Muscular Dystrophy Center: Washington, DC, USA, 2008.

42. Au, C.G.; Butler, T.L.; Sherwood, M.C.; Egan, J.R.; North, K.N.; Winlaw, D.S. Increased connective tissue growth factor associated with cardiac fibrosis in the mdx mouse model of dystrophic cardiomyopathy. Int. J. Exp. Pathol. 2011, 92, 57-65. [CrossRef]

43. Prabhu, S.D.; Frangogiannis, N.G. The biological basis for cardiac repair after myocardial infarction. Circ. Res. 2016, 119, 91-112. [CrossRef] [PubMed]

44. Wynn, T.A. Cellular and molecular mechanisms of fibrosis. J. Pathol. 2008, 214, 199-210. [CrossRef] [PubMed]

45. Mele, A.; Mantuano, P.; De Bellis, M.; Rana, F.; Sanarica, F.; Conte, E.; Morgese, M.G.; Bove, M.; Rolland, J.F.; Capogrosso, R.F.; et al. A long-term treatment with taurine prevents cardiac dysfunction in mdx mice. Transl. Res. 2019, 204, 82-99. [CrossRef] [PubMed]

46. Feng, R.; Wang, L.; Li, Z.; Yang, R.; Liang, Y.; Sun, Y.; Yu, Q.; Ghartey-Kwansah, G.; Sun, Y.; Wu, Y.; et al. A systematic comparison of exercise training protocols on animal models of cardiovascular capacity. Life Sci. 2019, 217, 128-140. [CrossRef] [PubMed]

47. Perrino, C.; Gargiulo, G.; Pironti, G.; Franzone, A.; Scudiero, L.; de Laurentis, M.; Magliulo, F.; Ilardi, F.; Carotenuto, G.; Schiattarella, G.G.; et al. Cardiovascular effects of treadmill exercise in physiological and pathological preclinical settings. Am. J. Physiol. Heart Circ. Physiol. 2011, 300, 1983-1989. [CrossRef]

48. Kemi, O.J.; Loennechen, J.P.; Wisløff, U.; Ellingsen, Y. Intensity-controlled treadmill running in mice: Cardiac and skeletal muscle hypertrophy. J. Appl. Physiol. 2002, 93, 1301-1309. [CrossRef]

49. Bellafiore, M.; Battaglia, G.; Bianco, A.; Palma, A. Expression pattern of angiogenic factors in healthy heart in response to physical exercise intensity. Front. Physiol. 2019, 10, 238. [CrossRef]

50. Zhou, X.; Xu, M.; Bryant, J.L.; Ma, J.; Xu, X. Exercise-induced myokine FNDC5/irisin functions in cardiovascular protection and intracerebral retrieval of synaptic plasticity. Cell Biosci. 2019, 9, 32. [CrossRef]

51. Schirone, L.; Forte, M.; Palmerio, S.; Yee, D.; Nocella, C.; Angelini, F.; Pagano, F.; Schiavon, S.; Bordin, A.; Carrizzo, A.; et al. A Review of the Molecular Mechanisms Underlying the Development and Progression of Cardiac Remodeling. Oxid. Med. Cell. Longev. 2017, 2017, 3920195. [CrossRef] 